\title{
Vacuum sieve tray for tritium extraction from liquid $\mathrm{Pb}-17 \mathrm{Li}$
}

$\operatorname{AUTHOR}(\mathrm{S})$ :

Okino, Fumito; Noborio, Kazuyuki; Yamamoto, Yasushi; Konishi, Satoshi

\section{CITATION:}

Okino, Fumito ... [et al]. Vacuum sieve tray for tritium extraction from liquid Pb-17Li. Fusion Engineering and Design 2012, 87(7-8): 1014-1018

ISSUE DATE:

2012-08

URL:

http://hdl.handle.net/2433/160052

\section{RIGHT:}

C 2012 Elsevier B.V.; この論文は出版社版でありません。引用の際には 出版社版をご確認ご利用ください。; This is not the published version. Please cite only the published version. 


\title{
Title
}

Vacuum sieve tray for Tritium extraction from liquid $\mathrm{Pb}-17 \mathrm{Li}$

\section{Authors}

Fumito Okino $^{\text {a }}$ Kazuyuki Noborio $^{b}$ Yasushi Yamamoto $^{c}$ Satoshi Konishi ${ }^{d}$

e-mail: fumito.okino@iae.kyoto-u.ac.jp

\author{
Affiliations \\ a; Graduate School of Energy Science, Kyoto University, Uji, Kyoto 611-0011, Japan \\ b; Institute of Sustainability Science, Kyoto University, Uji, Kyoto 611-0011, Japan \\ c; Faculty of Engineering Science, Kansai University, 3-3-35 Suita-shi, Osaka 564-8680, Japan \\ d; Institute of Advanced Energy, Kyoto University, Uji, Kyoto 611-0011, Japan
}

\begin{abstract}
Formation of droplet of liquid $\mathrm{Li}-17 \mathrm{~Pb}$ released from a nozzle into vacuum was studied for the evaluation of the feasibility as a tritium extraction process. Size of droplets formed from the nozzles was estimated by theoretical and experimental methods. For the theoretical estimation, the non-dimensional comparison of the physical bulk property of liquid $\mathrm{Pb}-17 \mathrm{Li}$ with water $\left(\mathrm{H}_{2} \mathrm{O}\right)$ at ambient temperature was applied. It was found to be reasonable to apply the Plateau-Rayleigh-Instability theory for the droplet size formula of the fluid $\mathrm{Pb}-17 \mathrm{Li}$ for the nozzle diameter $0.4 \mathrm{~mm}$ to $1.0 \mathrm{~mm}$, temperature $400^{\circ} \mathrm{C}$ to $500^{\circ} \mathrm{C}$, at initial velocity of $3 \mathrm{~m}$ per second. The experimental results of the droplet size showed good agreement with the theory. This device was used for the parametric study of extraction of deuterium during their free fall in vacuum. The scaling of the device suggests the engineering feasibility of the process.
\end{abstract}

\section{Keywords}

Vacuum-sieve-tray, Droplet, Pb-17Li, Diffusion, Plateau-Rayleigh-Instability (P.R.I.), Surface-tension

\section{Introduction}

Authors have proposed a concept of high temperature liquid $\mathrm{Pb}-17 \mathrm{Li}$ blanket and a process for recovery of tritium to be extracted from liquid droplets by diffusion in a vacuum-sieve-tray as depicted in Fig.1 for example. The ratio of tritium which is released from a sphere droplet under diffusion limited condition as a function of time is described as the equation below. [1]

$$
\frac{M_{t}}{M_{\infty}}=1-\frac{6}{\pi^{2}} \sum_{n=1}^{\infty} \frac{1}{n^{2}} \exp \left(-D n^{2} \pi^{2} t / a^{2}\right)
$$

Here $\quad t$ is diffusion time [sec]; $\quad a$ is radius of a droplet [m]; $\quad D$ is diffusion coefficient $\left[\mathrm{m}^{2} / \mathrm{sec}\right]$ It is easily seen that the radius of a droplet $a$ plays a pivotal role contributing to the tritium extraction. In due course the formula which explicates the radius of a droplet by its nozzle is a key tool for the basic design of vacuum-sieve-tray. Yamamoto et al. [2] has reported an experimental result of liquid $\mathrm{Pb}-17 \mathrm{Li}$ droplet formation and observed its radius is $0.9 \mathrm{~mm}$ by a nozzle of $1.0 \mathrm{~mm}$ diameter. Succeeding this work, this study intends to deduce a formula which describes the relationship between a droplet size and the radius of nozzle of liquid $\mathrm{Pb}-17 \mathrm{Li}$ and compare with experiment. Also the deuterium gas extraction was performed.

\section{Theory}

2.1 Modeling of a droplet formation and governing equation

The theory for water droplet [3] is based on the assumption that the undulation of the surface of liquid column is symmetrical to the $\mathrm{z}$-axis and is described as

$$
r=a+\alpha \cos k z
$$

Here as illustrated in Fig.2,

$k$ is wave-number defined by using wavelength $\lambda[\mathrm{m}]$ as $\quad k=2 \pi / \lambda \quad[1 / \mathrm{m}]$

$a$ is original liquid column radius $[\mathrm{m}]$. 
$\alpha$ is amplitude of the surface undulation [m] at time $t$ [sec] which is defined by using growth rate $q[1 / \mathrm{sec}]$ and initial amplitude $a_{0}[\mathrm{~m}]$ as

$$
\alpha=a_{0} e^{q t}
$$

And the deformation of liquid column is assumed to follow the surface energy minimizing condition. This condition is described by using a classic variational principle theory, namely Lagrange-Equation, as

$$
\frac{\partial L}{\partial q}-\frac{d}{d t}\left(\frac{\partial L}{\partial \dot{q}}\right)=0
$$

Here $L=T-U$ and $T$ mean the kinetic energy and $U$ is the potential energy respectively.

The potential energy of unstable column $U$ with a wave number $k$ is described by the difference of surface area and surface tension as

$$
U=\sigma\left(s-s_{0}\right)=-\sigma \frac{\pi \alpha^{2}}{2 a}\left(1-a^{2} k^{2}\right)
$$

Here $\sigma$ is surface tension $[\mathrm{N} / \mathrm{m}] \quad\left(s-s_{0}\right)$ is difference of surface area $\left[\mathrm{m}^{2}\right]$ between original cylindrical column and unstable column. Mathematical deduction detail is described in the Appendix-A.

The kinetic energy $T$ is described as below by using the radial velocity potential $\phi$ which is derived from a non-compressible continuity condition. Mathematical deduction detail is described in the Appendix B.

$$
T=\frac{1}{2} \rho \int_{S} 2 \pi a\left(\phi{\frac{\partial \phi}{\partial r_{r=a}}}\right) d z=\frac{1}{2} \pi \rho a^{2} \frac{I_{0}(k a) \dot{\alpha}^{2}}{k a I_{1}(k a)}
$$

Here $\rho$ is density $\left[\mathrm{Kg} / \mathrm{m}^{3}\right], I_{0} I_{1}$ are modified Bessel's equation of zero and first order. [6]

By merging these results into equation and using a boundary condition, finally growth rate of the instability $q$ is expressed as a function of only $k a$ and has a real value under the condition $1 \geq k a \geq 0$.

$$
q^{2}=\frac{\sigma}{a^{3} \rho} \frac{\left\{1-(k a)^{2}\right\}(k a) I_{1}(k a)}{I_{0}(k a)}
$$

2.2 Evolution of the unique wavelength and a droplet formation

The growth rate of the instability $\frac{q}{\sqrt{\frac{\sigma}{a^{3} \rho}}}$ written as a function of $k a$ is shown in Fig.3. It is seen that the growth rate $q$ has a maximum at $k a \cong 0.697$ be maximum $q \cong 0.343 \sqrt{\frac{\sigma}{a^{3} \rho}}$ then characteristic wavelength $\lambda_{1}$ is calculated as

$$
\lambda_{1}=\frac{2 \pi}{k} \cong \frac{2 \pi a}{0.697} \cong 9.0 a
$$

This result shows that a wave of liquid column of one unique wavelength overwhelms the various surface undulations and finally grows up to form droplets. By this mechanism, the droplet size is calculated from the equal volume of one droplet and one wave-length $\lambda_{1}$ liquid column, i.e. $\quad \frac{1}{6} \pi d_{d r o p l e t}^{3}=\pi a^{2} \lambda_{1} \cong 9.0 \pi a^{3}$. 
Then droplet size is expressed by using a nozzle diameter $D_{0}=2 a$ as a formula below.

$$
d_{\text {droplet }} \cong \frac{(9.0 \times 6)^{\frac{1}{3}}}{2} 2 a=1.89 D_{0} \quad[\mathrm{~m}]
$$

The characteristic time-constant of the growth of the instability $t_{g r}$ is calculated by inversing the growth rate $q$ as

$$
t_{g r}=1 / q \cong 1 /\left(0.343 \sqrt{\frac{\sigma}{a^{3} \rho}}\right) \quad[\mathrm{sec}]
$$

and in case of $\mathrm{Pb}-17 \mathrm{Li}$ at $400^{\circ} \mathrm{C}$ it is $4.8 \mathrm{msec}$.

\subsection{Verification of the theory applied for the liquid metal}

Non-dimensional normal direction stress equilibrium equation between droplet and vacuum ambience is express as

$$
-p_{d}{ }^{\prime}+\frac{1}{F r} z^{\prime}+\frac{2}{\operatorname{Re}} \mathbf{n} \cdot \mathbf{E}^{\prime} \cdot \mathbf{n}=\frac{1}{W e} \nabla^{\prime} \cdot \mathbf{n}
$$

Here $\quad R e=U_{c h} L_{c h} / v$ is "Reynolds number",

$$
\begin{aligned}
& F r=U_{c h}{ }^{2} / g L_{c h} \text { is "Froude number" represents Inertia vs. Gravity } \\
& W e=\rho U_{c h}{ }^{2} L_{c h} / \sigma \quad \text { is "Weber number" represents Inertia vs. Surface tension. }
\end{aligned}
$$

Comparison of these three characteristic parameters is shown in Table 1. It shows that liquid $\mathrm{Pb}-17 \mathrm{Li}$ at the temperature of $400^{\circ} \mathrm{C}$ to $500^{\circ} \mathrm{C}$ is in surface tension dominating phase and belongs to the same regime with that of water at $20^{\circ} \mathrm{C}$. Then it is reasonable to presume both materials show similar behavior at temperature above mentioned so the equation for water droplet is applicable also for the liquid $\mathrm{Pb}-17 \mathrm{Li}$ droplet analysis. All bulk properties used for calculation is summarized in Table 1.

\subsection{Effective range of the formula}

The largest length considered by the above equations is defined as Froude number equals with Weber number and it is described as

$$
L_{c h X}=\sqrt{\frac{\sigma}{\rho g}} \quad[\mathrm{~m}]
$$

In case of $\mathrm{Pb}-17 \mathrm{Li}$ at $400^{\circ} \mathrm{C}$ the critical length is calculated as $2.2 \mathrm{~mm}$ and in case of water at $20^{\circ} \mathrm{C}$ it is $2.7 \mathrm{~mm}$.

\section{Experimental}

\subsection{Experimental setup}

A schematic of experimental setup is shown in Fig.4 and in Fig.5. It is consisted of a reservoir, nozzles with various radii, sight windows, diffusion chamber, gas accumulation pump, vacuum pump and instruments.

Sizes are: the upper reservoir of $\phi 150 \mathrm{~mm} \times 100 \mathrm{~mm} \mathrm{~h}$, four nozzles with diameter from $\phi 0.4 \mathrm{~mm}$ to $\phi 1.0 \mathrm{~mm}$, the lower diffusion-chamber of $\phi 150 \mathrm{~mm} \times 500 \mathrm{~mm} \mathrm{~h}$ with observation windows. Deuterium and argon gas are supplied for the diffusion measurement. The nozzle is formed by drilling and finished for the $\mathrm{Pb}-17 \mathrm{Li}$ droplet and for the water formed injection needles were used. Chambers and nozzles were kept in temperature from $300^{\circ} \mathrm{C}$ to $500^{\circ} \mathrm{C}$. Diameter of the droplet was estimated from volumetric average and compared with photo. The volume of the dropped liquid was measured from a pressure difference in the upper chamber with the digital manometer-1 in Fig.4. Total number of droplets are measured by the high speed movie system VW-9000 of Keyence (4000 frames per sec.). Average diameter is calculated as it is a sphere shape, and its size variation and deviation from the sphere were observed from the photo images. 


\section{Results and considerations}

\subsection{Observation of $\mathrm{Pb}-17 \mathrm{Li}$ liquid droplet formation}

As shown in Fig.6, it was observed that the liquid $\mathrm{Pb}-17 \mathrm{Li}$ at $400^{\circ} \mathrm{C}$ drawn from the nozzle made a liquid column at first then only unique wavelength overwhelms the column surface and finally formed same size droplets. This complies with the theoretical analysis result.

\subsection{Measurement of droplet shape}

Measured diameters of droplets along $\mathrm{X}$ and $\mathrm{Y}$ axis are shown in Fig.7 and Fig.8. The droplet shape was roughly sphere and the sphericity defined as $\mathrm{X} / \mathrm{Y}$ ranged from 0.7 to 1.3 considered to be caused by a vibrating motion.

\subsection{Comparison with the theory}

The measured droplet diameter of $\mathrm{Pb}-17 \mathrm{Li}$ at $400^{\circ} \mathrm{C}$ as a function of nozzle diameter, also droplet diameter of water at $20^{\circ} \mathrm{C}$ are shown in Fig.9. In case of water, theoretical formula well describes the experimental result. In case of $\mathrm{Pb}-17 \mathrm{Li}$, droplet diameter also agreed with the formula in a limited size region. At the nozzle diameter of $1.0 \mathrm{~mm}$ resultant droplet size deviates $5 \%$ from the theoretical value to the smaller side and it is presumed due to the influence of the effective range of this formula which is described by the equation(1.12). This result suggests that it can be used for the control of the size of liquid metal droplet by using prescribed nozzle size from which metal is extruded.

\subsection{Extraction of the deuterium gas from the $\mathrm{Pb}-17 \mathrm{Li}$ droplet}

The release of absorbed deuterium gas from liquid droplets of $\mathrm{Pb}-17 \mathrm{Li}$ was measured with a $\Phi 1.0 \mathrm{~mm}$ nozzle. Deuterium gas was dissolved in the liquid $\mathrm{Pb}-17 \mathrm{Li}$ in the upper chamber before the run of each experiment and time for equilibration was set to satisfy the long enough time for diffusion. Released deuterium from the droplets was collected with a vacuum pump. Dissolved amount was also estimated from the previously reported data [9] as follows, and plotted in a chart.

$\begin{array}{llll}\text { Solubility; } & \mathrm{K}_{\mathrm{S}}=2.8 \times 10^{-7} \exp \left(-1.54 \times 10^{4} / \mathrm{RT}\right) & {\left[\text { at. frac. } / \mathrm{Pa}^{1 / 2}\right]} & \text { by P. Calderoni } \\ \text { Diffusivity; } & \mathrm{D}=4.0 \times 10^{-8} \exp \left(-1.95 \times 10^{4} / \mathrm{RT}\right) & {\left[\mathrm{m}^{2} / \mathrm{sec}\right]} & \text { by F. Reiter }\end{array}$

Fig.10 shows the amount of recovered deuterium as the function of loading pressure and release temperature. The amount of recovered gas showed the square root relationship with the dissolution pressure. This result suggests that the dissolution of deuterium in the $\mathrm{LiPb}$, if the majority was recovered as expected, is in the dissociated form. Amount of the recovered deuterium was one order different with the reference calculation under the assumption of diffusion controlled release. This suggests the possibility of different mechanism of deuterium transportation in the liquid metal droplet.

\section{5 Feasibility of vacuum-sieve-tray}

Based on the above results, the extraction ratio of deuterium by multi-stack vacuum-sieve-tray is evaluated by formula (1.1) under following design configuration.

Nozzle; $\quad \Phi 0.5 \mathrm{~mm}$ I.D. x $1.2 \times 10^{6}$ nozzles with $4 \mathrm{~mm}$ pitch initial flow velocity $3 \mathrm{~m} / \mathrm{sec}$

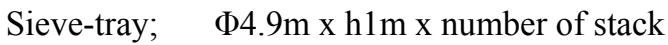

Temperature; $400^{\circ} \mathrm{C}, 425^{\circ} \mathrm{C}, 450^{\circ} \mathrm{C}, 500^{\circ} \mathrm{C}$

Diffusivity coefficients; by F. Reiter $\mathrm{D}=4.0 \times 10^{-8} \exp \left(-1.95 \times 10^{4} / \mathrm{RT}\right) \quad\left[\mathrm{m}^{2} / \mathrm{sec}\right]$;

Fig.11 shows the recovery ratio of deuterium from vacuum sieve tray and it depends on the liquid temperature and diffusivity coefficients and expected to be designed to satisfy the requirements for the tritium recovery in the blanket system.

\section{Conclusion}

The formula to express the diameter of liquid $\mathrm{Pb}-17 \mathrm{Li}$ droplet is theoretically deduced by applying a surface minimizing theory. Under surface tension dominating regime, it is described only by using the nozzle diameter as

$$
d_{\text {droplet }} \cong 1.89 D_{0} . \quad \text { Here } D_{0} \text { means a nozzle diameter }[\mathrm{m}] .
$$


This formula was compared with the experimental results and it described the size of droplet $\mathrm{Pb}-17 \mathrm{Li}$ well. This result can be used for the vacuum-sieve-tray design by controlling the size of droplets in it.

The extraction of deuterium gas in a vacuum from droplets of liquid $\mathrm{Pb}-17 \mathrm{Li}$ was tested. The recovery of the deuterium suggested that it complied with the solution and release process but the amount of gas was one order different anticipated from the previously reported solubility and diffusivity. However the results suggest the feasibility of the tritium extraction from liquid metal using vacuum-sieve-tray. The diffusion mechanism that was not measured in this experiment will need further study.

\section{Acknowledgement}

This work is done with enlightening suggestions by Prof. Hoshide and Imatani Graduate School of Energy Science Kyoto Univ., sophisticated picture takings by Mr. Imoto of Sugawara Labs, Mr.Ochi of Keyence Corp.

\section{Appendix A Difference of undulating surface area}

Surface area of undulating column per length is

$$
S_{u n}=\frac{2 \pi}{\lambda} \int_{0}^{\lambda} d l=\frac{2 \pi}{\lambda} \int_{0}^{\lambda} r\left(1+\frac{1}{2}\left(\frac{d r}{d z}\right)^{2}\right) d z \simeq \pi a\left(2+\frac{1}{2} \alpha^{2} k^{2}\right)
$$

Volume of undulating column per length is

$$
v_{\text {un }}=\frac{\pi}{\lambda} \int_{0}^{\lambda} r^{2} d z=\pi\left(a^{2}+\frac{\alpha^{2}}{2}\right) \text { then } a \simeq \sqrt{\frac{v_{u n}}{\pi}}\left(1-\frac{\pi \alpha^{2}}{4 v_{u n}}\right)
$$

By AA1 and AA2 the difference of surface area per unit length $\left(s-s_{0}\right)$ is described as

$$
\left(s-s_{0}\right) \simeq \frac{\pi \alpha^{2}}{2 a}\left(a^{2} k^{2}-1\right)
$$

\section{Appendix B kinetic energy by velocity potential}

Velocity potential $\phi$ is defined as $v=\nabla \phi$ then kinetic energy $T$ is described as $T=\frac{1}{2} \rho \int_{V} v^{2} d V=\frac{1}{2} \rho \int_{V}(\nabla \phi) \cdot(\nabla \phi) d V \quad(\mathrm{AB} 1) \quad$ and by using Green's first identity (AB1) is modified

$$
\frac{1}{2} \rho \int_{V}(\nabla \phi) \cdot(\nabla \phi) d V=\frac{1}{2} \rho \int_{S} \phi \nabla \phi \cdot d S=\frac{1}{2} \rho 2 \pi \int r \phi \frac{\partial \phi}{\partial r} d z \quad \because d S=2 \pi r d z \quad \mathbf{n} \cdot \nabla=\frac{\partial}{\partial r}
$$

Due to continuity condition $\nabla^{2} \phi=0 \quad \phi$ is described as $\phi=A \mathrm{~J}_{0}(i k r) \cos k z$

here $\mathrm{J}_{0}(x)$ is Bessel function of order zero. By AB2 and AB3 finally kinetic energy $T$ is described $T=\frac{1}{2} \rho a^{2} \frac{\mathrm{I}_{0}(k a) \dot{\alpha}^{2}}{k a \mathrm{I}_{0}^{\prime}(k a)} \quad$ here $\mathrm{I}_{0}(x)$ is modified Bessel function or order zero. 


\section{References}

[1] J. Crank, The Mathematics of Diffusion, Sec. 4, 6, Oxford University Press, ISBN 978-0-19-853411-2.

[2] Y. Yamamoto et al., Design of Tritium collecting system from LiPb dropping experiment, Fusion science and Technology Volume 60 Number 2 p558-562, Proceedings of the Nineteenth Topical Meeting on the Technology of Fusion Energy (TOFE) Part2 Aug. 2011

[3] Lord Rayleigh, On the instability of jets, Proceedings of the London mathematical society, Vol.10 1878, pp. 4-7

[4] S. Chandrasekhar, Hydrodynamic and Hydromagnetic Stability, Chapter X, Dover Publications, Inc. ISBN-10:0-486-64071-X

[5] Pierre-Gilles de Gennes et al., Capillarity and Wetting Phenomena Trans. by A. Reisinger, Sec. 5.2.4, Springer, ISBN 0-387-00592-7.

[6] M. Abramowitz et al., Handbook of Mathematical Functions, Sec. 9.6.27, Dover Publications, Inc, ISBN-10: 0-486-61272-4.

[7] Y.C. Fung, A first course in Continuum Mechanics Third Edition, Sec.7.3, Prentice Hall, ISBN 0-13-061524-2.

[8] E. Mas de les Valls et al., Lead-lithium eutectic material database for nuclear fusion technology, J. Nucl. Mater. 376 (2008)

353-357

[9] P. Calderoni et al., Measurement of hydrogen and deuterium solubility in the eutectic lead-lithium alloy, P3.90 Poster/Topic H : Fuel Cycle and Breeding Blankets: $25^{\text {th }}$ SOFT Symposium on Fusion Technology, 15-19 Sept. 2008.

[10] F. Reiter, Solubility and diffusivity of hydrogen isotopes in liquid Pb-17Li, Fusion Engineering and Design 14 (1991) 207-211 North-Holland 


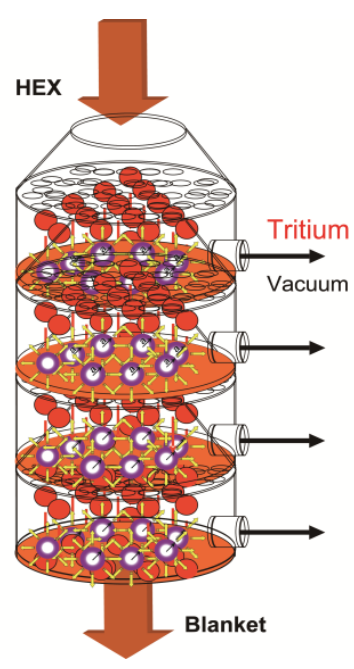

Fig.1 Vacuum-sieve-tray image

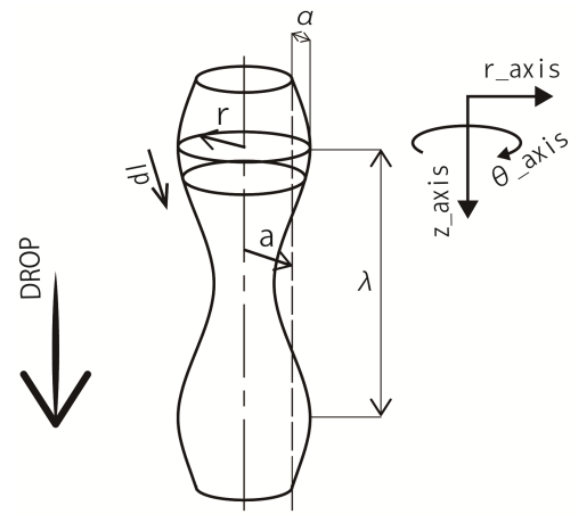

Fig.2 Coordinate system and notation diagram of droplet formation

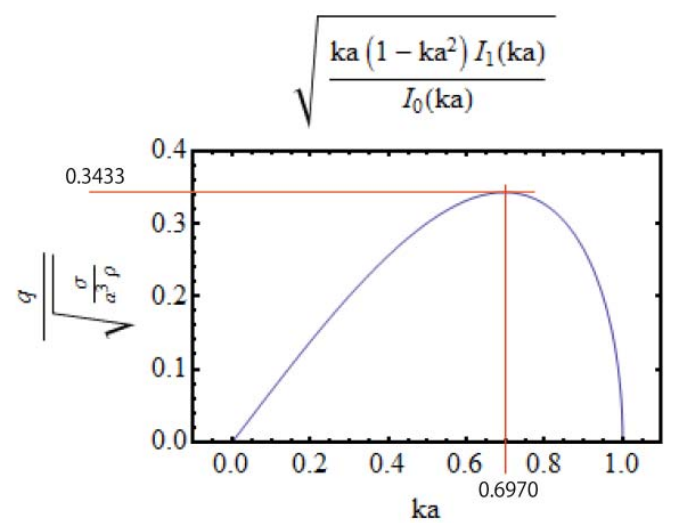

Fig.3 Growth rate q normalized vs. wave-number ka 


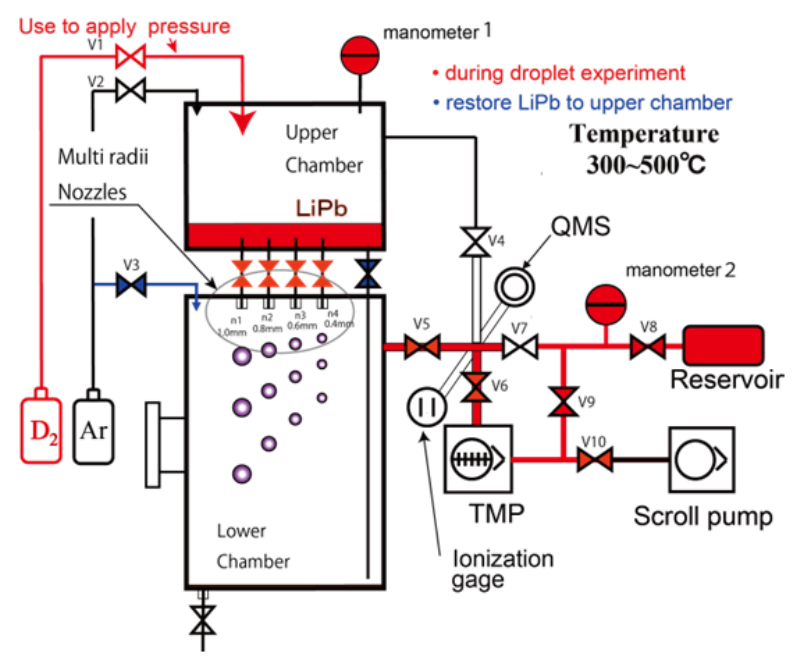

Fig.4 Schematic diagram of the experimental setup

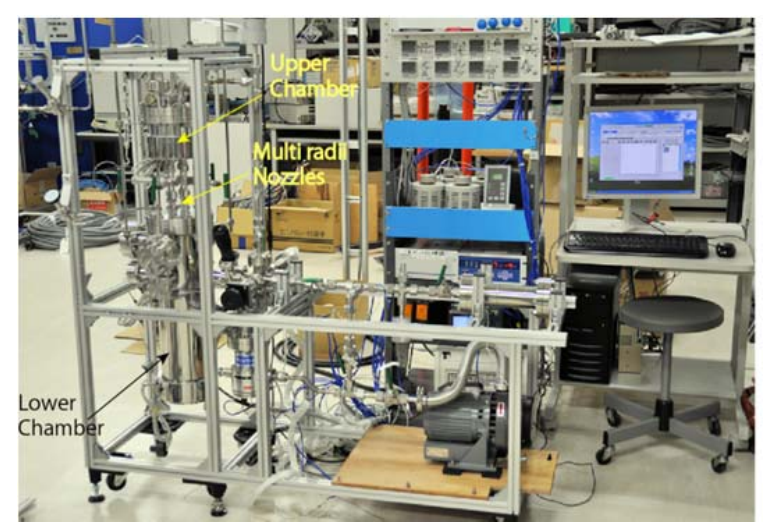

Fig. 5 Whole view of the experimental setup

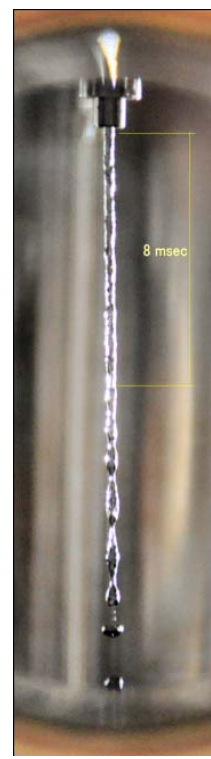

Fig.6 Liquid column and droplets by $1.0 \mathrm{~mm}$ dia. nozzle in a vacuum sieve tray 


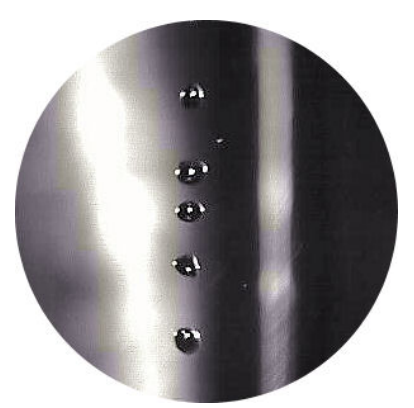

Fig.7 Droplets by $0.6 \mathrm{~mm}$ nozzle

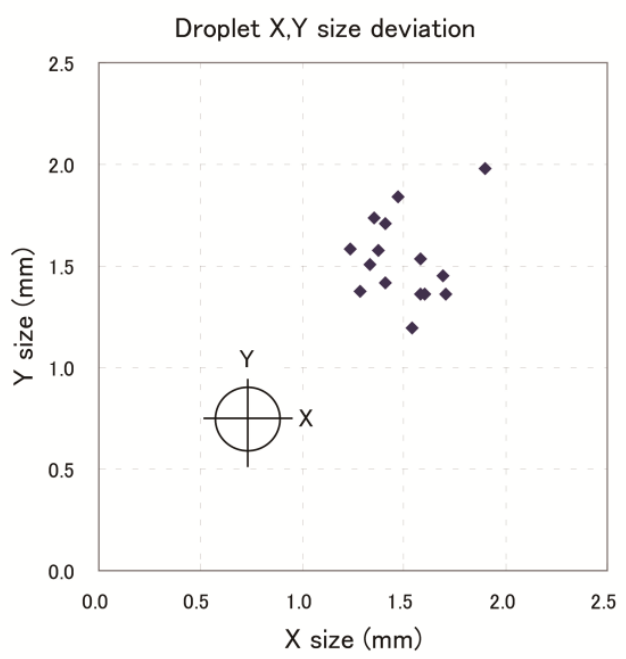

Fig. 8 XY deviation of droplet diameter

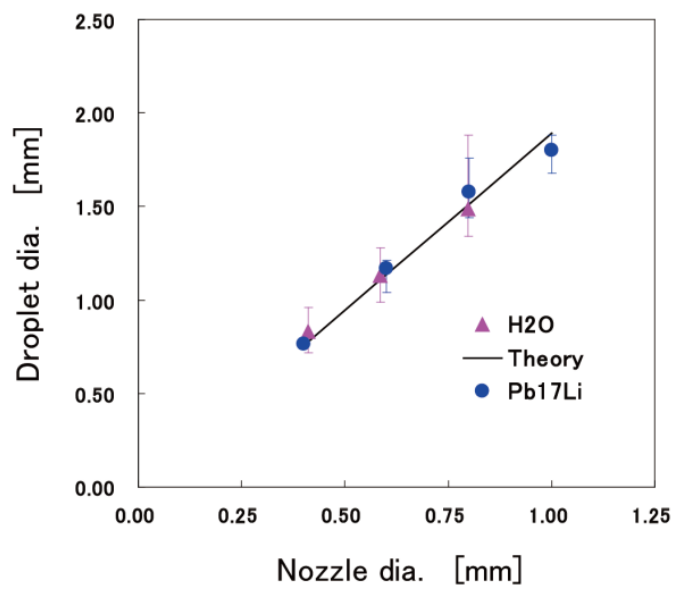

Fig.9 Experimental result of droplet diameter vs. liquid column 


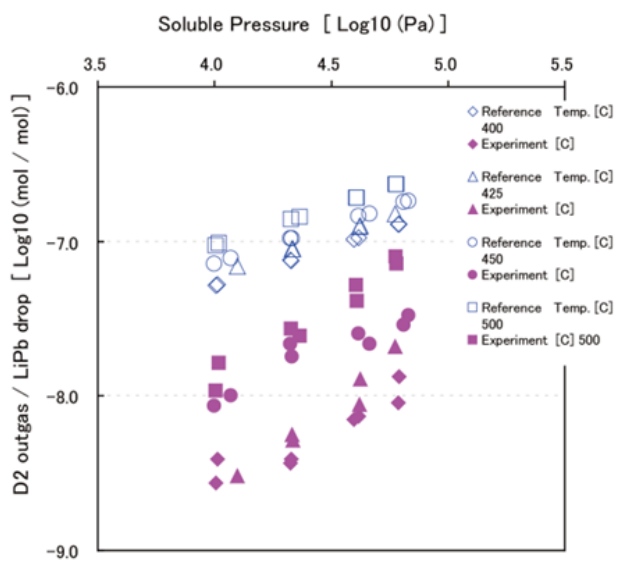

Fig.10 Experimental result of D2 release gas as a function of soluble pressure

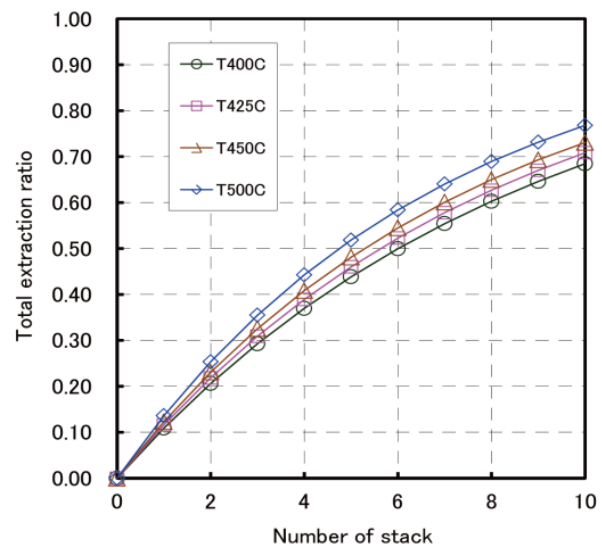

Fig.11 Total extraction ratio as a function of stacks

\section{Tables}

Table 1 Comparison table of the normalized numbers

\begin{tabular}{|l|l|l|l|l|l|l|l|l|l|}
\hline & Density & Viscosity & $\begin{array}{l}\text { Surface } \\
\text { tension }\end{array}$ & Temperature & Velocity & Length & $\begin{array}{l}\text { Reynolds } \\
\text { number }\end{array}$ & $\begin{array}{l}\text { Froude } \\
\text { number }\end{array}$ & $\begin{array}{l}\text { Weber } \\
\text { number }\end{array}$ \\
\cline { 2 - 10 } & $\rho$ & $\mu$ & $\sigma$ & $T$ & $U$ & $L$ & $R e$ & $F r$ & $W e$ \\
\cline { 2 - 10 } & $\mathrm{Kg} / \mathrm{m}^{3}$ & $N \mathrm{sec} / \mathrm{m}^{2}$ & $N / m$ & Celsius & $m / \mathrm{sec}$ & $m$ & $U L / V$ & $U^{2} / g L$ & $\rho U^{2} L / \sigma$ \\
\hline $\mathrm{H}_{2} \mathrm{O}$ & $1.0 \times 10^{3}$ & $1.0 \times 10^{-3}$ & $0.7 \times 10^{-1}$ & 20 & 3 & $1.0 \times 10^{-3}$ & $3.0 \times 10^{3}$ & $9.2 \times 10^{2}$ & $1.3 \times 10^{2}$ \\
\hline $\mathrm{Pb}-17 \mathrm{Li}$ & $9.7 \times 10^{3}$ & $1.5 \times 10^{-3}$ & $4.5 \times 10^{-1}$ & 400 & 3 & $1.0 \times 10^{-3}$ & $1.9 \times 10^{4}$ & $9.2 \times 10^{2}$ & $2.0 \times 10^{2}$ \\
\hline $\mathrm{Pb}-17 \mathrm{Li}$ & $9.6 \times 10^{3}$ & $1.2 \times 10^{-3}$ & $4.4 \times 10^{-1}$ & 500 & 3 & $1.0 \times 10^{-3}$ & $2.5 \times 10^{4}$ & $9.2 \times 10^{2}$ & $2.0 \times 10^{2}$ \\
\hline
\end{tabular}

